Check for updates

Cite this: RSC Adv., 2017, 7, 22515

\title{
Crystallization and morphological transition of poly(L-lactide)-poly( $\varepsilon$-caprolactone) diblock copolymers with different block length ratios
}

\author{
Weiqiang Han, ${ }^{a}$ Xia Liao, (D) *a Qi Yang, ${ }^{a}$ Guangxian Li, ${ }^{a}$ Bin He, ${ }^{a}$ Wenli Zhu ${ }^{b}$ \\ and Zengheng $\mathrm{HaO}^{* \mathrm{c}}$
}

\begin{abstract}
The crystallization behavior, banded spherulite and morphological transition of poly(L-lactide) (PLLA) phases within the block copolymers were investigated. All experimental results showed that the structure and thermal properties of PLLA-PCL copolymers could be adjusted by varying the ratios of the chain length of the two blocks. Morphological results indicated that the banded spherulites of PLLA formed when PLLArich copolymers crystallized. PCL segments introduced unbalanced stresses around PLLA lamellar crystals, which resulted in a bending moment responsible for twisting of PLLA lamellar crystals. As the block length ratio of PCL to PLLA increased, an over accumulation of PCL segments influenced the twisting of PLLA lamellae. In addition, it was interesting to find that the banded spherulite morphology changed with increasing the crystallization temperature. The crystallization temperature has an effect on the relationship between the sense of lamellar twisting and the morphological transition of PLLA, which is reflected in the fact that the band spacing of banded spherulites showed strong temperature dependence when the crystallization temperature exceeds $115{ }^{\circ} \mathrm{C}$, while it exhibited weak temperature dependence below $115^{\circ} \mathrm{C}$. In particular, above $125^{\circ} \mathrm{C}$ the band spacing disappeared and nonbanded spherulites formed.
\end{abstract}

Received 26th March 2017
Accepted 13th April 2017
DOI: 10.1039/c7ra03496b
rsc.li/rsc-advances

\section{Introduction}

Poly(L-lactide) (PLLA) and poly(e-caprolactone) (PCL) are two kinds of biocompatible and biodegradable materials that have been widely employed in the industrial and medical field. ${ }^{1-4}$ For commercial products, the applications of PLLA to packaging films and agricultural materials are limited by its low thermal stability and brittleness, especially under impact loading. ${ }^{5}$ In contrast, PCL has high flexibility and a relatively low $T_{\mathrm{g}}$ and is easier to process than PLLA but its strength and melting point are relatively low for various applications. ${ }^{6,7}$ Therefore, the copolymerization of PLLA with PCL is known to be an effective route to improve properties in comparison with each individual component. ${ }^{8,9}$ In a copolymer, when one block can crystallize, the physical properties and degradability of other blocks will be affected since the morphology can also be dramatically altered at the microscale level. ${ }^{10-12}$ It has been confirmed that the PLLAPCL copolymer is weakly segregated in the melt depend on

${ }^{a}$ College of Polymer Science and Engineering, State Key Laboratory of Polymer Materials Engineering, National Engineering Research Center for Biomaterials, Sichuan University, Chengdu 610065, Sichuan, China. E-mail: xliao@scu.edu.cn; Tel: +86-28-8540-8361

${ }^{b}$ School of Mechanical and Automobile Engineering, Hubei University of Arts and Science, Xiangyang, 441053, Hubei, China

${ }^{c}$ Chongqing Zhixiang Paving Technology Engineering Co., Ltd., Chongqing 400060, China.E-mail: haozengheng@cmhk.com composition, ${ }^{13,14}$ and the melting and crystalline temperature of the PLLA block are higher than those of the PCL block. Thus, the PLLA block crystallizes first without any confinements and produces a specific morphology during the cooling process, which can or cannot be modified upon crystallization of the other blocks..$^{15}$ Such modification depends on the cooling rate, crystallization temperature, and the block length ratio between the block components. Hamley et al. studied the sequential crystallization of PLLA in double crystalline PLLA-PCL diblock copolymers and found that the crystallization structure, thermodynamics and kinetics of the biodegradable PLLA block can be influenced by coupling to biodegradable PCL in double crystalline diblock copolymers. ${ }^{13}$ Afterward, Castillo et al. investigated the crystallization kinetics and morphology of PLLA and PCL blocks within a series of PLLA-PCL double crystalline diblock copolymers and found that the reorganization ability of the PLLA block increased with PCL content. ${ }^{16}$ Wang et al. synthesized well-defined star-shaped PCL-PLLA copolymers and founded that the band spherulites with no obvious Maltese cross patterns were formed, ${ }^{17}$ but the detailed formation mechanism of the banded texture of PLLA within the star-shaped PCL-PLLA copolymer was not analyzed.

It is well known that the banded texture of PLLA have been widely observed and studied in its blends with other components such as poly(ethylene oxide) (PEO), ${ }^{18,19}$ poly ( $\varepsilon$-caprolactone) (PCL) ${ }^{20}$ poly(3-hydroxybutyrate) $\quad(\mathrm{PHB})^{21}$ and poly(ethylene glycol) (PEG), ${ }^{22}$ and rhythmic growth and lamellar 
twisting theories have been proposed for the formation mechanism of the unique spherulites. ${ }^{23-25}$ However, in the system of block copolymers, ${ }^{17,26,27}$ the formation of banded texture of PLLA become quite complicated because of the strong molecular interaction, microphase separation and constrained geometry of each block, which make the investigations on banded spherulites of the block copolymers consisting of PLLA blocks are still under discussion and not yet clarified up to now. Moreover, considering the structural diversity of the block copolymers and the above literature review, there is still lack of intuitive cognition about the banded spherulites of PLLA-PCL copolymers, and no results have been reported on the block length ratio and crystallization temperature on crystalline morphology of PLLA blocks. Therefore, it is quite essential to investigate the morphological features for this block copolymer, which will contribute to understanding the relationship between the block architecture and the corresponding crystalline morphologies.

For this purpose, we synthesized a wide series of linear PLLA-PCL diblock copolymers in which the block length of PLLA is varied, while that of PCL is constant. The crystallization behavior and banded spherulite of PLLA blocks within the copolymers were investigated with differential scanning calorimetry, polarized optical microscope, scanning electronic microscopy and atomic force microscopy. In this research, we found that PLLA blocks could form banded spherulites in linear PLLA-PCL diblock copolymers from the melt for the first time, and the banded spherulites depended on the crystallization temperature and the block length ratio between the block components. In addition, combining with the relationship between the lamellar thickness and spherulitic growth rate, we further disclosed the mechanism of banding-to-nonbanding morphological transition.

\section{Experimental part}

\section{Materials}

The PCL and PLLA homopolymers and their diblock copolymers were synthesized and characterized as reported earlier. ${ }^{28}$ In this work, the PLLA-PCL diblock copolymer was represented by PCLLA, and the number average molecular weight and the weight fraction (wt\%) of each block were summarized in Table 1.

Table 1 Molecular characteristic of the block copolymers and homopolymers

\begin{tabular}{lllll}
\hline & $\begin{array}{l}\text { Mn of PLLA } \\
\left(\mathrm{g} \mathrm{mol}^{-1}\right)\end{array}$ & $\begin{array}{l}\text { Mn of PCL } \\
\left(\mathrm{g} \mathrm{mol}^{-1}\right)\end{array}$ & $\begin{array}{l}\text { PLLA } \\
(\mathrm{wt} \%)\end{array}$ & $\begin{array}{l}\text { PCL } \\
(\mathrm{wt} \%)\end{array}$ \\
\hline PLLA & 6000 & & & \\
PCLLA75 & 18000 & 6000 & 100.0 & \\
PCLLA63 & 10000 & 6000 & 75.0 & 25.0 \\
PCLLA57 & 8000 & 6000 & 62.5 & 37.5 \\
PCLLA50 & 6000 & 6000 & 57.0 & 43.0 \\
PCLLA40 & 4000 & 6000 & 50.0 & 50.0 \\
PCLLA14 & 1000 & 6000 & 40.0 & 60.0 \\
PCL & & 6000 & 14.3 & 85.7 \\
& & & & 100.0
\end{tabular}

\section{Casting film}

The obtained polymer powders were dissolved in dichloromethane at room temperature to produce a solution with concentration of $1 \mathrm{wt} \%$. A drop of solution was cast onto cleaned glass wafers and then was placed under vacuum oven at room temperature for 1 week to remove the residual solvent.

\section{Etching}

The volume ratio of $1: 2$ water-methanol mixtures containing $0.025 \mathrm{~mol} \mathrm{~L}^{-1}$ of sodium hydroxide was used for etching experiments. ${ }^{29}$ The crystallized samples were then subjected to etching in the mixed solution at $60{ }^{\circ} \mathrm{C}$ for $5 \mathrm{~h}$; subsequently the etched surface was cleaned by using distilled water. A fieldemission SEM (Inspect F, FEI, Finland) was utilized to investigate the crystalline morphology of the etched samples.

\section{Differential scanning calorimetry (DSC)}

The thermal properties of PLLA and PCL phases in the block copolymers as well as those of neat PLLA and PCL homopolymers were measured by DSC TA Q20 with indium standard and nitrogen atmosphere. Each sample of about $7 \mathrm{mg}$ was first heated to $200{ }^{\circ} \mathrm{C}$ for $5 \mathrm{~min}$ to eliminate the crystalline residues and subsequently cooled at a rate of $10^{\circ} \mathrm{C} \min ^{-1}$ to $-20^{\circ} \mathrm{C}$, and then heated to $200{ }^{\circ} \mathrm{C}$ again at the same cooling rate. DSC thermal diagrams of all the samples were obtained from the second heating runs and cooling runs.

\section{Polarized optical microscopy (POM)}

The microstructure morphology of PLLA phases in the block copolymers as well as those of neat PLLA sample were studied by a BX51 polarized optical microscope (POM) (Olympus; Tokyo, Japan) equipped with a camera system and a Linkam CSS450 hot stage. Two types of temperature control procedures were adopted for isothermal crystallization. In the first procedure, each sample film on glass wafers was heated to $180{ }^{\circ} \mathrm{C}$ over the melting temperature, to remove the thermal history and prior crystals for $5 \mathrm{~min}$, and then the hot stage was cooled at a rate of $10{ }^{\circ} \mathrm{C} \min ^{-1}$ to $100,110,117$ and $125{ }^{\circ} \mathrm{C}$, and kept at the crystallization temperature until all the spherulites impinged with each other. In the second procedure, which is termed as 'twostep crystallization'. Firstly, the melted specimen of PCLLA75 was cooled to $120{ }^{\circ} \mathrm{C}$ for a while, after a period of time, the heating stage was further heated to $130{ }^{\circ} \mathrm{C}$ to crystallize until spherulite covered the entire field of vision. Secondly, the PCLLA75 sample was treated with $130{ }^{\circ} \mathrm{C}$ to crystallize, some time later, the heating stage was cooled to $120{ }^{\circ} \mathrm{C}$ until PLLA segments fully crystallized. The sizes of the growing spherulites were measured by Image-Pro Plus software at appropriate intervals of time, and the spherulitic growth rate $(G)$ of PLLA spherulites were calculated from the slopes of the lines obtained by plotting the spherulite radius against time.

\section{Atomic force microscopy (AFM)}

The surface morphologies and microstructures of the films were observed at room temperature by atomic force microscopy 
(AFM) (MFP-3D-BIO, Asylum Research, USA) with tapping mode. Both height and phase images were acquired simultaneously. Silicon cantilever tip with resonance frequency of approximately $300 \mathrm{kHz}$ and a spring constant of about $40 \mathrm{~N} \mathrm{~m}^{-1}$ were applied in all experiments.

\section{Results and discussion}

\section{Thermal and crystallization behavior of PLLA-PCL}

The thermal behaviors of nonisothermal crystallization of PLLA-PCL diblock copolymers as well as those of neat PLLA and PCL homopolymers were investigated by DSC. Fig. 1(a) and (b) show the thermal diagrams measured during both heating and cooling at $10{ }^{\circ} \mathrm{C} \mathrm{min}^{-1}$, respectively. All thermal properties obtained from DSC scans are listed in Table 2. In general, the crystallization temperatures $\left(T_{\mathrm{c}}\right)$ and the melting temperatures $\left(T_{\mathrm{m}}\right)$ of PCL blocks within the copolymers are lower than that of the PCL homopolymer and decrease with increasing the molecular weight of PLLA blocks. This is associated with the fact that the earlier crystallization of the PLLA blocks strongly restricts the crystallization of the PCL blocks. Furthermore, the $T_{\mathrm{m}}$ of neat PLLA is lower than that of most of their copolymers while the $T_{\mathrm{c}}$ values show the opposite phenomenon, indicating that the existence of PCL blocks affect the crystallization and melting behavior of the PLLA blocks. Among the copolymers, the $T_{\mathrm{m}}$ of PLLA blocks increase with increasing the content of PLLA, which can be explained by two reasons: (1) PCL segments are trapped in the intraspherulitic regions, which influence the crystalline perfection of PLLA blocks, so that the melting temperature of PLLA blocks decrease. ${ }^{15}$ (2) PCL blocks can act as a diluent depressing the $T_{\mathrm{m}}$ of the PLLA blocks. ${ }^{30}$ However, what is noteworthy is that the $T_{\mathrm{c}} \mathrm{S}$ of the PLLA blocks within the copolymers have a large scatter with composition. This is because the $T_{\mathrm{c}}$ of the PLLA blocks within the copolymers during the cooling scans is influenced not only by composition but also by the molecular weight and nucleation density. ${ }^{16}$

In addition, the PLLA block still remains amorphous within the PCLLA14 copolymer because the low component of PLLA is
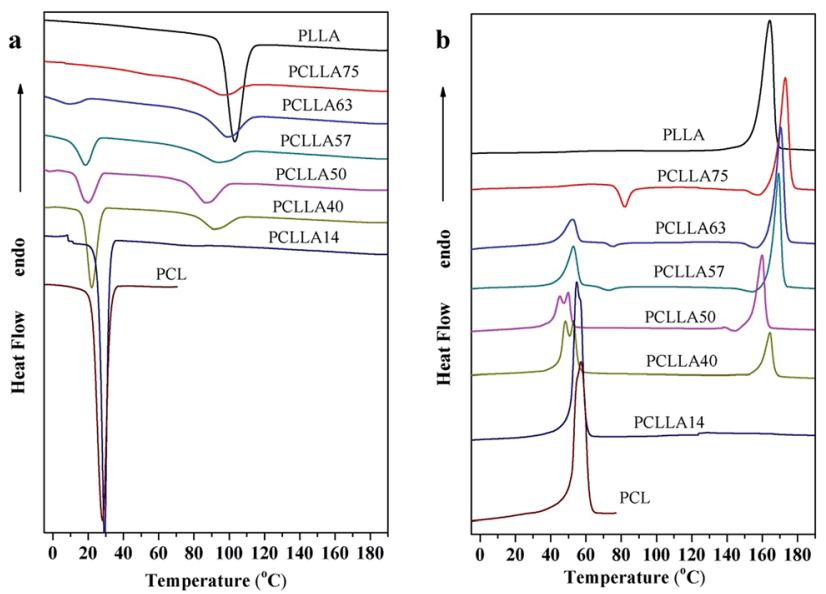

Fig. 1 DSC thermograms of PLLA-PCL copolymers and their homopolymers: (a) first cooling traces and (b) second heating traces. confined within quite small microstructures. In the case of PCLLA40 and PCLLA50, the melting of the PCL blocks can be clearly seen as an endothermic double peak, indicating that fractionated crystallization occurs. The higher-temperature signal indicates the melting of the crystals form during cooling from the melt while the lower temperature peak is due to room temperature annealing of the thinner lamellar population in the sample. ${ }^{14}$ When PLLA block is the major component within the PLLA-PCL diblock copolymers, PCL can't crystallize either. But a very interesting phenomenon can be observed in Fig. 1(b), that is, the PLLA blocks show two exothermic peaks within the diblock copolymers with PLLA contents above 50 wt $\%$ : the one at around $80{ }^{\circ} \mathrm{C}$ is called cold crystallization temperature $\left(T_{\mathrm{cc}}\right)$, a higher value of $T_{\mathrm{cc}}$ would mean that PLLA crystallize later during the DSC scan and hence indicate a slower crystallization rate, ${ }^{31}$ and the other one appears just before the main melting peak. Both of exothermic peaks shift to lower temperature with the decrease of PLLA content. At PLLA content is less than $50 \mathrm{wt} \%$, only the main fusion endotherms of PLLA and PCL are observed.

The crystallinity $\left(X_{\mathrm{c}}\right)$ of PLLA and PCL phases within the block copolymers as well as those of neat PLLA and PCL homopolymers were calculated by means of the following equation: ${ }^{32}$

$$
\Delta X_{\mathrm{c}}(\%)=\frac{\Delta H_{\mathrm{m}}-\Delta H_{\mathrm{cc}}}{w \Delta H_{\mathrm{m}}^{0}} 100
$$

where $\Delta H_{\mathrm{m}}$ and $\Delta H_{\mathrm{cc}}$ are the experimental melting enthalpy and cold crystallization enthalpy of PLLA or PCL crystals, respectively, and $w$ is the weight fraction of PLLA or PCL in diblock copolymers. A value of $\Delta H_{\mathrm{m}}^{0}$ is the melting enthalpy for $100 \%$ crystalline of PLLA or PCL. $\Delta H_{\mathrm{m}}^{0}=93.7 \mathrm{~J} \mathrm{~g}^{-1}$ (ref. 33 and 34) and $135.3 \mathrm{~J} \mathrm{~g}^{-1}$ (ref. 35) are used for PLLA and PCL, respectively. The variations of the $X_{\mathrm{c}}$ of PCL and PLLA plotted against the PLLA weight fraction is shown in Fig. 2. As can be seen from Fig. 2, the $X_{\mathrm{c}}$ of PCL blocks within PLLA-PCL diblock copolymers are obviously lower than that of the PCL homopolymer. The $X_{\mathrm{c}}$ of PCL is affected by the composition and decrease continuously with increasing the $w_{\text {PLLA }}$. Especially in PCLLA75, the crystallization of PCL can't be observed because of the confinement effect of PLLA. On the other hand, the $X_{\mathrm{c}}$ of PLLA blocks increase rapidly with increasing $w_{\text {PLLA }}$ from 0 to 0.57 , however, it decreases gradually with the further increase of $w_{\text {PLLA }}$, which can be explained by the dilution effect and the confinement effect. At PLLA contents $<57 \mathrm{wt} \%$, the dilution of PCL as well as the depression of melting point reduce the crystallization driving force, which may enhance the crystallinity. As the increase of PLLA compositions, the confinement effect within nanodomains induced by microphase separation may reduce the crystallinity.

\section{Effect of composition on banded spherulite of PLLA-PCL}

Fig. 3 shows the POM micrographs of PLLA-PCL copolymers and neat PLLA melt-crystallized at $117^{\circ} \mathrm{C}$, since $117^{\circ} \mathrm{C}$ is higher than the $T_{\mathrm{m}}$ of PCL, only PLLA can crystallize at this temperature. From the POM micrographs, it can be found that in 
Table 2 Thermal properties obtained from DSC scans

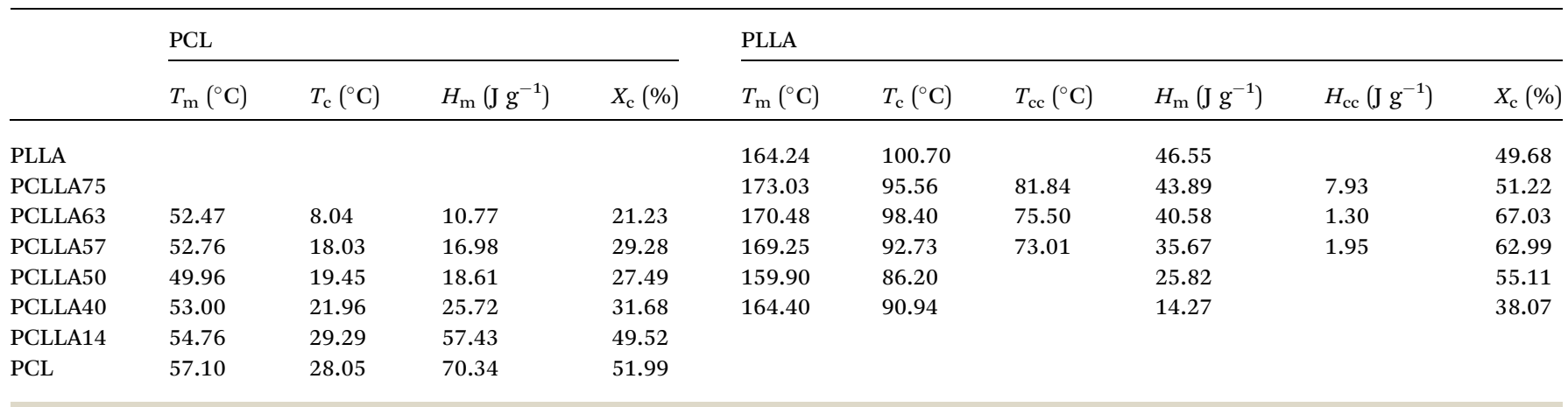

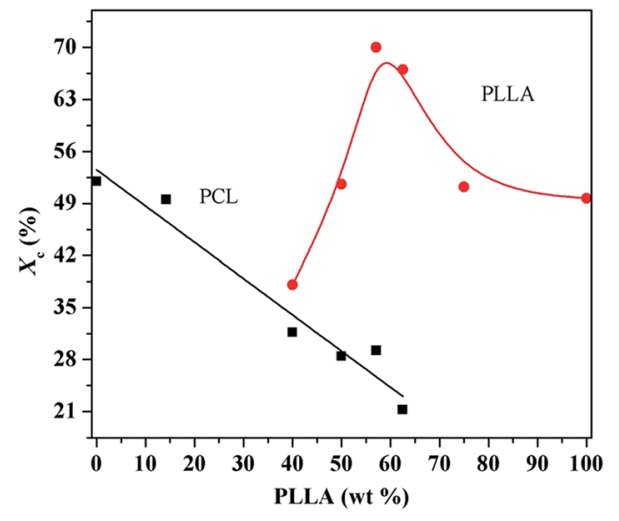

Fig. 2 Crystallinity of PCL and PLLA blocks as functions of the PLLA weight fraction.

addition to PCLLA14, PLLA homopolymer and other PLLA-PCL copolymers can form spherulite under this condition. In the case of PCLLA14, the spherulite can't be detected due to the low component of PLLA, which is consistent with the DSC results. It is interesting that the typical spherulites form in PLLA homopolymer. Contrary to the pure PLLA, in the PCL-rich copolymers, PLLA spherulites show the coarse texture and irregular boundary, and the conventional Maltese-cross is also disrupted. The segments of PCL migrate to the PLLA spherulitic surface region at $117^{\circ} \mathrm{C}$, so that the coarse texture is observed. However, in the PLLA-rich copolymers, PLLA spherulites show the conventional Maltese-crossed. Moreover, it should be noticed that PCLLA63 forms the irregular banded spherulites, while the clear and regular banded texture appear in the PCLLA75 spherulites. This may be associated with the fact that the small amount of PCL blocks induces the PLLA lamellar twisting along the radial growth direction. ${ }^{36}$ When the sample is retained at room temperature for a period of time, the morphology of the banded spherulites of the PLLA blocks are expected to be maintained. The PCL blocks crystallize within the amorphous interlamellar spaces of the PLLA spherulites, which does not generate any effect on the banded spherulites of the PCLLA75 copolymer.

The radius variation of neat PLLA homopolymer and PLLAPCL diblock copolymers are plotted against the crystallization time during isothermal crystallization at $T_{\mathrm{c}}$ of $117^{\circ} \mathrm{C}$ as shown in Fig. 4(a). It can be seen that PLLA spherulites measured from optical micrographs all grow linearly with time and that the spherulitic growth rates $(G)$ can be calculated from the slopes of the linearly fitted lines. Fig. 4(b) shows the spherulitic growth rates for the homo-PLLA and PLLA blocks within the PLLA-PCL copolymers at $117{ }^{\circ} \mathrm{C}$ with various amount of PLLA. As can be seen from the Fig. 4(b), the spherulitic growth rates of PLLA blocks are smaller than that of PLLA homopolymer, and the $G$ of PLLA crystals obtained at $117{ }^{\circ} \mathrm{C}$ decreases with the increase of PLLA content. Such decrease of $G$ with increasing the PLLA component could not only be ascribed to the influence of the block length of PLLA but also of the dilution effect of PCL. In the PLLA-PCL diblock copolymers, the entanglement effect of the molecular chain increase with increasing the block length of PLLA, which hinder the movement of PLLA segments. In

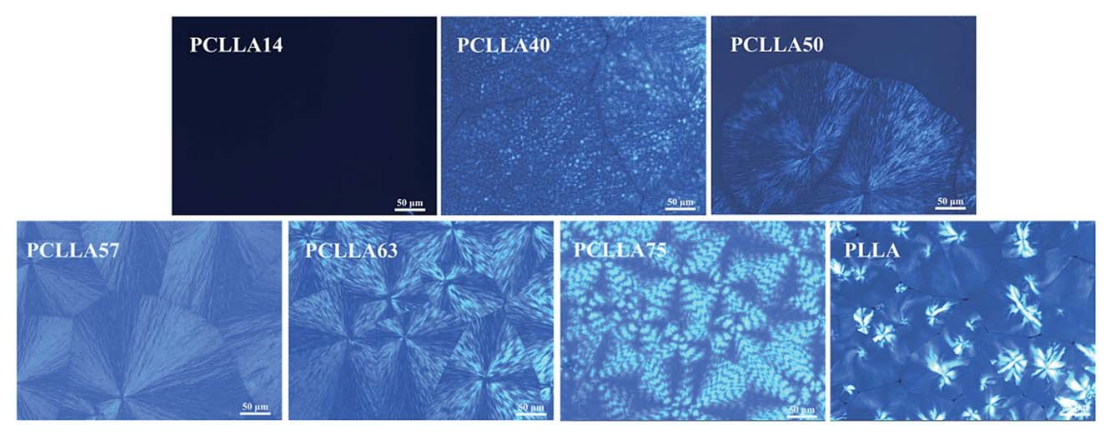

Fig. 3 Polarizing optical micrographs of PLLA-PCL copolymers and pure PLLA spherulites isothermally crystallized at $117^{\circ} \mathrm{C}$. 

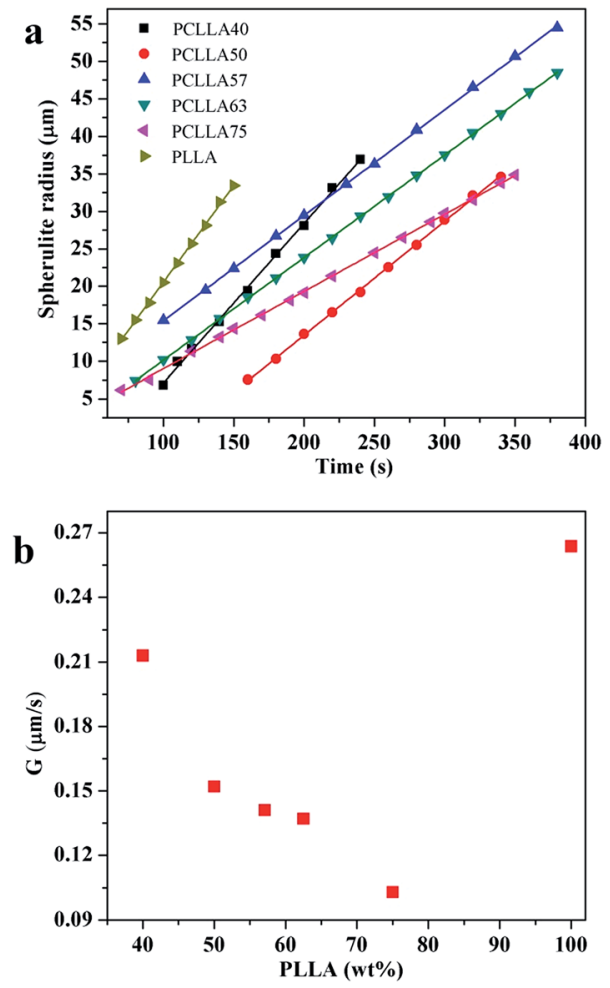

Fig. 4 (a) Changes in spherulite radius as functions of crystallization time in neat PLLA homopolymer and PLLA-PCL diblock copolymers during isothermal crystallization at $T_{\mathrm{C}}$ of $117^{\circ} \mathrm{C}$. (b) The growth rate of PLLA spherulite as a function of the PLLA weight fraction.

addition, PCL can act as a diluent to promote the segmental mobility associated with crystallization for PLLA because PCL possesses a relatively low $T_{\mathrm{g}}$, which is also supported by the decreased $T_{\text {cc }}$ with increasing PCL. As a consequence, the spherulitic growth rate of PLLA increases with the decrease of PLLA content.

As observed, PLLA can show banded or nonbanded texture depend on the component of diblock copolymers. In order to further investigate spherulitic structure of PLLA-PCL diblock copolymers, we utilize a SEM to record the phase images of the crystalline morphologies of PCLLA57 and PCLLA75. Fig. 5 presents the SEM images of etched PCLLA57 conventional spherulites and PCLLA75 banded spherulites. From the Fig. 5( $\left.\mathrm{a}_{1}\right)$, the PCL and a leftover of looser amorphous PLLA locate in the intercrystalline amorphous regions are removed by etching. The stripe ravines form on the surface of PCLLA57 spherulites and extend outward from the center. Besides, the lamellae arrange in parallel and the parallel lamellae grow into branch can be distinctly seen in Fig. $5\left(\mathrm{a}_{2}\right)$. The continuous lamellae grow along the radius direction, no ring bands can be obtained. ${ }^{37}$ For the PCLLA75 spherulites obtained at $117{ }^{\circ} \mathrm{C}$, both the Maltese-cross and extinction rings can be clearly observed under crossed-polarized light. As can be seen from the Fig. $5\left(b_{1}\right)$ and $\left(b_{2}\right)$, many crevices along the radius direction appear because the amorphous parts between edge-on lamellae are easier to be eroded than the amorphous parts between flaton lamellae, ${ }^{38}$ indicating that the edge-on and flat-on lamellar

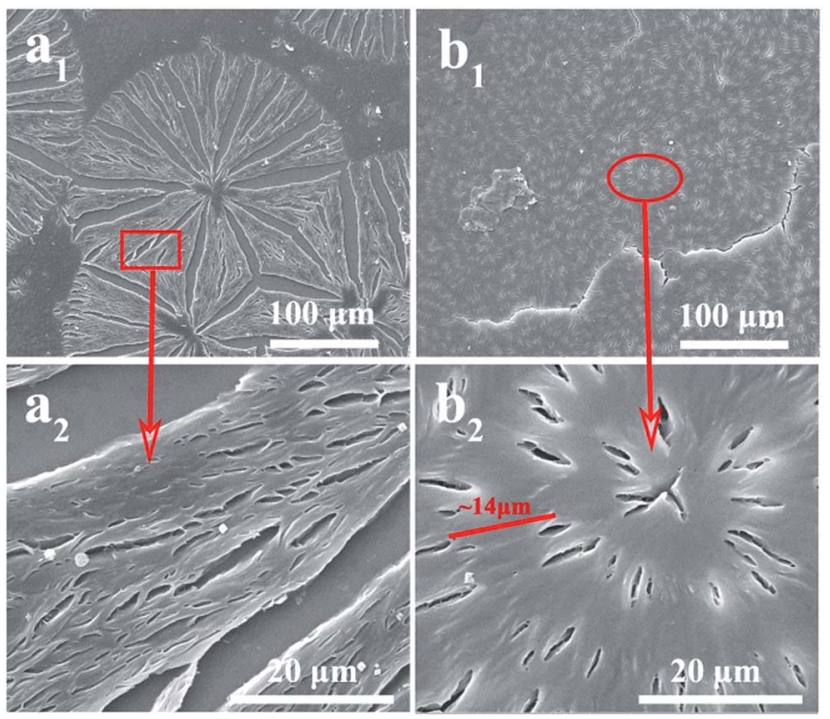

Fig. 5 SEM images of (a) PCLLA57 and (b) PCLLA75 spherulites crystallized at $117^{\circ} \mathrm{C}$.

stacks coexist in PCLLA75 banded spherulites. In addition, we also observed that the distance $(\sim 14 \mu \mathrm{m})$ between the adjacent crevices is approximately equal to the pitch length $(\sim 14.52 \mu \mathrm{m})$ of the banded texture observed by POM, which reflect that the formation of alternating flat-on-to-edge-on morphology for the cause of the extinction bands in POM images.

To get more lamellar information of PCLLA57 and PCLLA75 spherulites, AFM is employed. Fig. 6 shows the AFM images of spherulites with different magnitudes during meltcrystallization at $117^{\circ} \mathrm{C}$. The micrograph in Fig. $6\left(a_{1}\right)$ is a low magnification AFM height image of the PCLLA57 spherulite. The ordinary spherulite is observed, and the lamellae arrange in parallel and the parallel lamellae grow into branch are also seen in Fig. $6\left(a_{2}\right)$ and $\left(a_{3}\right)$, the enlarged AFM phase images, denote as the square part in Fig. $6\left(\mathrm{a}_{1}\right)$ and $6\left(\mathrm{a}_{2}\right)$, respectively. However, unlike PCLLA57 spherulite, many light spots appear on PCLLA75 spherulitic surface, and the average relative height difference in PCLLA75 spherulite is estimated about $50 \mathrm{~nm}$. This thickness variation is unsufficient to cause bands of such strong birefringence contrast between ridge and valley. ${ }^{39}$ Higher magnification phase images of the ellipse part of this spherulite are presented in Fig. $6\left(b_{2}\right)$ and $\left(b_{3}\right)$, respectively. From the Fig. $6\left(b_{2}\right)$, PCLLA75 crystalline lamellae spread out like palm tree leaves, and the leaves are lamellae bundles, not single layer lamellae (see Fig. 6( $\left.b_{3}\right)$ ). Besides, it should be noticed that the growing direction of leaves show a deflection, which can be ascribed to crystalline lamellar twisting. In general, with regard to the origin of the lamellar twisting, the structural discontinuities caused by the sum of the screw dislocations and the continuous lamellar twisting results from an unbalanced surface stress repartition are generally considered. ${ }^{\mathbf{2 6 , 4 0 - 4 2}}$ Apparently, the second interpretation is more common than the first one as has been confirmed in many polymers. In addition, Lotz and Cheng also proposed that unbalanced stresse from the lamellar surfaces was the origin for the twisting of lamellae in 

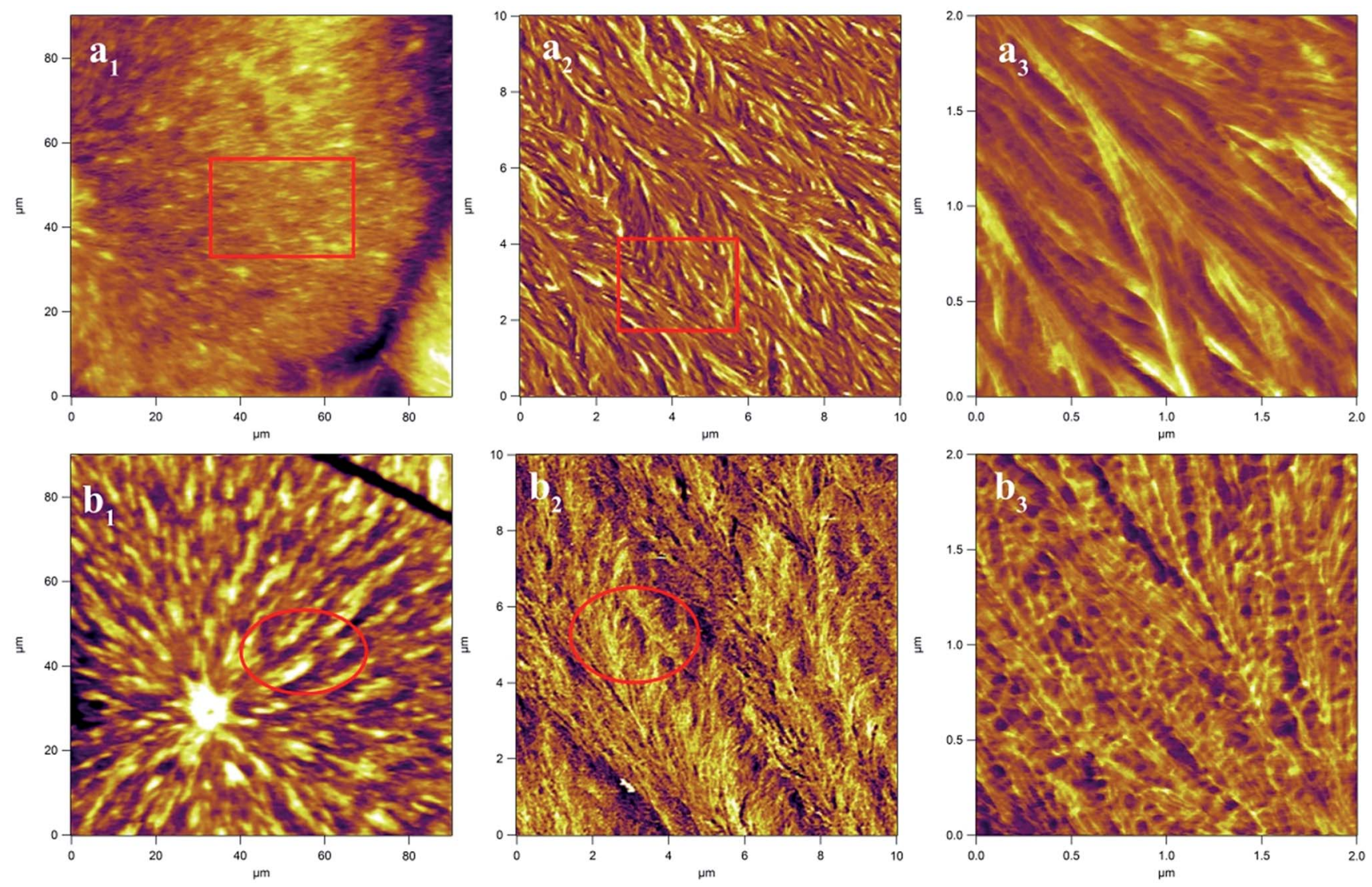

Fig. 6 The AFM images of (a) PCLLA57 and (b) PCLLA75 spherulites with different magnitudes isothermally crystallized at $117{ }^{\circ} \mathrm{C}$. $\left(a_{1}\right)$ and $\left(a_{2}\right)$ : height image; $\left(a_{2}\right),\left(a_{3}\right),\left(b_{2}\right)$ and $\left(b_{3}\right)$ : phase image.

chiral polymers. ${ }^{40}$ From the Fig. $5(\mathrm{~b})$, it can be seen that there is no obvious boundary between the rings formed by the flat-on and edge-on lamellae, suggesting that the twisting of the lamellae is continuous. This result indeed demonstrates that the lamellar twisting of PCLLA75 banded spherulites originates from unbalanced surface stress as suggested by Lotz and Cheng.

Obviously, based on the analysis above, in PLLA-PCL copolymers, the regions between the lamellae are occupied by amorphous PLLA chains and a spot of amorphous PCL segments, and combining with the fact that the banded spherulites only be formed in PLLA-PCL copolymers. It is reasonable to conclude that the unbalanced surface stress is initiated and disturb the regular orientation of crystalline lamellae of PLLA by the small population of PCL segments around the PLLA lamellar structures. In addition, as the increasing block length ratio of PCL to PLLA, the over accumulation of PCL segments influence the twist of PLLA lamellae, which result in the non-banded structure in other copolymers.

\section{Effect of temperature on banded spherulite of PLLA-PCL}

According to the morphological results discussed above, the banded spherulite can be obtained more easily in PLLA-rich copolymers. To examine the effect of temperature on the spherulitic morphology, especially banded spherulite, PCLLA75 diblock copolymer is selected to crystallize at 100, 110, 117 and $125^{\circ} \mathrm{C}$, respectively, and the relevant photographs are shown in Fig. 7.

As can be seen from the Fig. 7, many small spherulites are found at $T_{\mathrm{c}}$ of $100{ }^{\circ} \mathrm{C}$, and the size of PLLA spherulites increase gradually when $T_{\mathrm{c}}$ increases. Besides, it should be noticed that the less number of spherulites form in the field of vision because of the low nucleation in $125{ }^{\circ} \mathrm{C}$. In addition, the

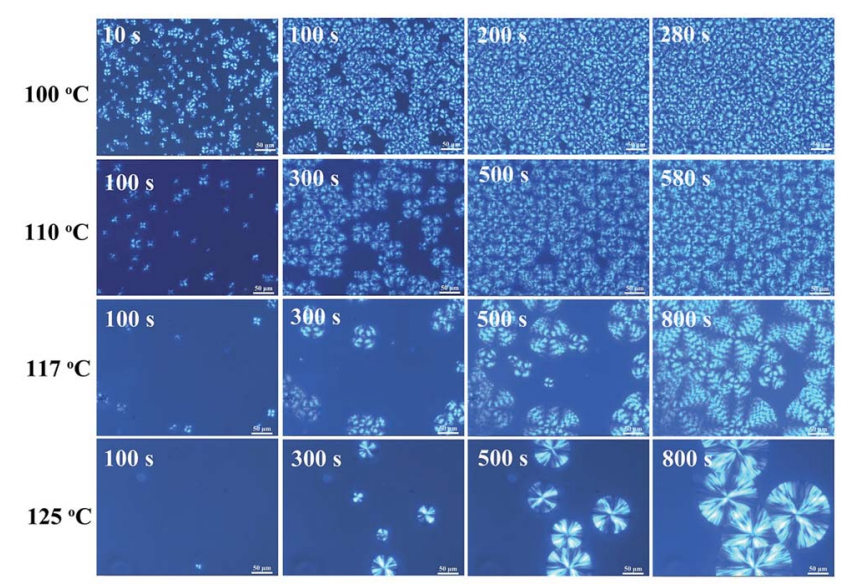

Fig. 7 Polarizing optical micrographs of PCLLA75 spherulites isothermally crystallized at $100,110,117$ and $125^{\circ} \mathrm{C}$. 
nucleation in the crystallization process obviously decreases and the time for PLLA spherulites to fill up the entire field of vision obviously increases with increasing the crystallization temperature due to the decreasing undercooling degree. Also, banded spherulites with ringed extinctions are observed at $T_{\mathrm{c}}$ of 100-117 ${ }^{\circ} \mathrm{C}$. Moreover, it is worth noting that the banded spherulites cannot grow larger due to impingements of spherulites at $T_{\mathrm{c}}$ of $100{ }^{\circ} \mathrm{C}$, and the banded texture in PCLLA75 spherulites do not form when it crystallized at $125^{\circ} \mathrm{C}$. To further investigate inherent relationship between the banded morphology and crystallization temperature, in this section, the band spacing and the growth rates of PCLLA75 spherulites at various temperatures are measured from the POM images.

Fig. 8 shows the changes in band spacing and spherulitic growth rate as functions of crystallization temperature in PCLLA75 copolymer. As shown in Fig. 8, a bell-shaped curve for the $T_{\text {c }}$ dependence of $G$ can be found. ${ }^{43}$ We observe that the growth rate of PLLA spherulite increases with crystallization temperature in the range from 100 to $120^{\circ} \mathrm{C}$, and it reaches the peak at $120{ }^{\circ} \mathrm{C}$, then further increasing crystallization temperature, $G$ decreases. In addition, the band spacing of PCLLA75 spherulites show a monotonic increasing trend with increasing the crystallization temperature, and the increased band spacing in spherulites agree with the result reported by Sasaki et al. ${ }^{\mathbf{4 4}}$ Furthermore, it is also noted that the band spacing of PCLLA75 spherulites show strong temperature dependence when crystallization temperature $\left(T_{\mathrm{c}}\right)$ exceeds $115{ }^{\circ} \mathrm{C}$, while that exhibit weak temperature dependence below $115^{\circ} \mathrm{C}$.

\section{Band to nonband morphological transition}

As seen in Fig. 7, it is interesting that PCLLA75 copolymer can show banded or non-banded spherulites depend on the crystallization temperature. To explore this morphological transition better, we conduct "two-step isothermal crystallization" experiments. Fig. 9 shows POM micrographs of PCLLA75 spherulites melt-crystallized under two-step crystallization. It should be noted that for two-step crystallization, the first crystallization temperature $\left(T_{\mathrm{c} 1}\right)$ is set as $120^{\circ} \mathrm{C}$ and the second crystallization temperature $\left(T_{\mathrm{c} 2}\right)$ is set as $130{ }^{\circ} \mathrm{C}$. From the Fig. 9(a), the first step isothermal crystallization encounter banded spherulites, while ringless spherulites appear along

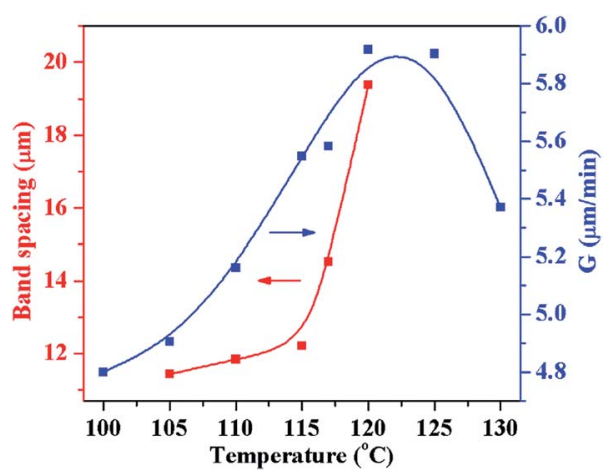

Fig. 8 The band spacing and spherulitic growth rate of PCLLA75 spherulite as functions of the crystallization temperature.

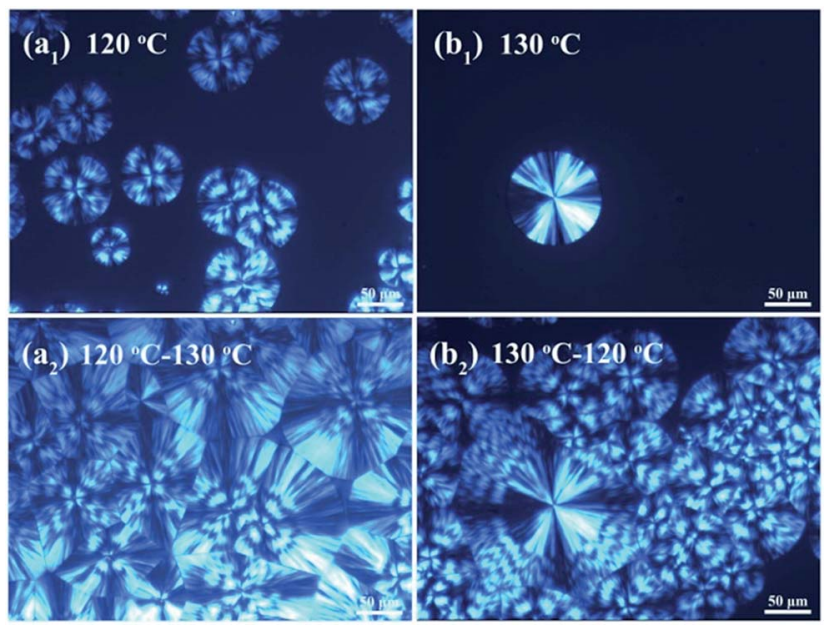

Fig. 9 Polarizing optical micrographs of PCLLA75 spherulite crystallized under two-step isothermal crystallization.

bands edge at higher second crystallization temperature. Another two-step isothermal crystallization experiment is shown in Fig. 9(b), the first crystallization temperature $\left(T_{\mathrm{c} 1}\right)$ is set as $130{ }^{\circ} \mathrm{C}$ and the second crystallization temperature $\left(T_{\mathrm{c} 2}\right)$ is set as $120{ }^{\circ} \mathrm{C}$. On the contrary, ordinary spherulites form at $130{ }^{\circ} \mathrm{C}$. However, when the crystallization temperature drop to $120{ }^{\circ} \mathrm{C}$, banded spherulites appear at the edge of the ordinary spherulites and continue to grow along the original spherulitic direction until the spherulites impinge on the neighbors. The temperature dependence of the morphology explicitly indicates that the cause of the lamellar twisting should be related to the crystal growth of the PCLLA75 spherulite.

As an important parameter of banded spherulites, the average spacing of the extinction bands, corresponding to the half-pitch length of twisted lamellae, manifests lamellar twisting frequency, which is related to the causes of lamellar twisting. ${ }^{45,46}$ From Fig. 8 and 9, we note that the band spacing of spherulites vanished as temperature exceeds $125^{\circ} \mathrm{C}$ and that the radius of the nonbanded spherulite obtained at $130{ }^{\circ} \mathrm{C}$ is much higher than the band spacing of the banded spherulites obtained at $120{ }^{\circ} \mathrm{C}$. Hence, it is reasonable to presume that the nonbanded spherulites obtained at $130{ }^{\circ} \mathrm{C}$ lack any lamellar twisting. This implies that, at the special $T_{\mathrm{c}}$, the correlation between the sense of unbalanced surface stress and the lamellar structure of PLLA is lost, which will be discussed in more detail in a latter section.

It is believed that a higher crystallization temperature apparently leads to increase of the lamellar thickness, ${ }^{45,47}$ which makes the lamellar twisting more difficult and is beneficial to generate the larger band space. When PLLA blocks within PCLLA75 copolymer crystallize at the lower temperature, much thinner PLLA lamellae form. The thinner PLLA lamellae twist more easily under the unbalanced stresses induced by the PCL chains, resulting in much higher twisting frequency of PLLA lamellae and smaller band spacing. Similarly, the thicker PLLA lamellae form with increasing the crystallization temperature, generating the larger band spacing. On the other hand, the 
spherulitic growth rate increase with increasing the temperature can also be seen from Fig. 8, the faster diffusion rate of the PCL blocks into the PLLA lamellae, resulting in the enhanced unbalanced surface stresses on PLLA lamellae, which apparently lead to a higher twisting frequency of PLLA lamellae to decrease the band spacing accordingly. However, due to the competition between the lamellae thickening and the increased spherulitic growth rate, the band spacing of PCLLA75 spherulite exhibits weak temperature dependence below $115{ }^{\circ} \mathrm{C}$. On the contrary, when temperature over $115{ }^{\circ} \mathrm{C}$, the lamellar thickening effect on increasing the band spacing is dominant, this makes the band spacing increasing dramatically. With further increasing the temperature above $125{ }^{\circ} \mathrm{C}$, the lamellar twisting vanishes and the nonbanded spherulite appears because of the synergy effect between the lamellae thickening and the decreased spherulitic growth rate.

Based on the analysis above, $T_{\mathrm{c}}$ plays a critical role in banding-to-nonbanding morphological transition. In order to further check whether this behavior of the possible role of $T_{\mathrm{c}}$ in the correlation between the spherulitic morphology and the crystallization temperature also exist in other specimens, neat PLLA and other PLLA-rich diblock copolymers are selected to crystallize at different temperatures. Fig. 10 shows the POM micrographs of neat PLLA, PCLLA57 and PCLLA63 spherulites

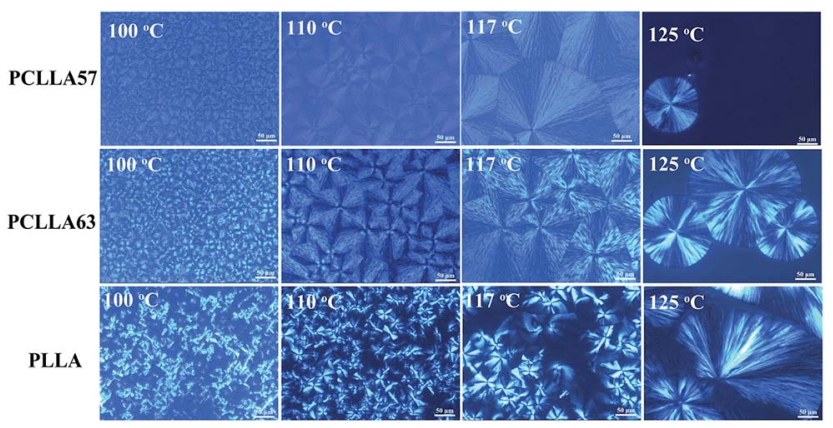

Fig. 10 The polarizing optical micrographs of neat PLLA, PCLLA57 and PCLLA63 spherulites isothermally crystallized at 110, 110, 117 and $125^{\circ} \mathrm{C}$.

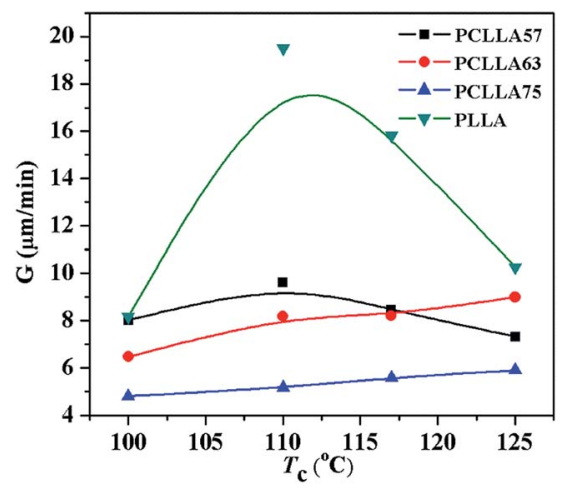

Fig. 11 The spherulitic growth rate of PLLA block as functions of the crystallization temperature for PLLA-PCL copolymers and PLLA homopolymer. melt-crystallized at $100,110,117$, and $125{ }^{\circ} \mathrm{C}$, respectively. As can be seen from the Fig. 10, the banding-to-nonbanding morphological transition cannot take place except for the change of the number and size of spherulites at different crystallization temperatures. As for the PCLLA57 and PCLLA63, the over accumulation of PCL segments fail to induce the periodic twisting of PLLA lamellae, even though there are the relatively faster mobility of PCL segments compared with PCLLA75 spherulite (Fig. 11). This indicates that the banding-tononbanding morphological transition dependency on the $T_{\mathrm{c}}$ is closely correlated to the block architecture.

\section{Conclusions}

In this work, the crystallization behavior and morphology of PLLA-PCL diblock copolymers with different ratios of the chain length were investigated. Both $T_{\mathrm{c}}$ and $T_{\mathrm{m}}$ of PLLA blocks within the copolymers are affected by composition and decrease with the increase of $w_{\mathrm{PCL}}$, while the $X_{\mathrm{c}}$ of PLLA increase rapidly and then decrease gradually with the increase of $w_{\text {PLLA }}$ due to the diluent and confinement effects.

It was observed that only PCLLA75 copolymers can form the clear banded spherulite, which indicates that the formation of banded spherulites within PLLA-PCL diblock copolymers is closely correlated to the composition of the block copolymers. PCL segments are trapped into the PLLA spherulites, inducing the unbalanced stresses around PLLA lamellar crystals. In addition, with the increasing block length ratio of PCL to PLLA, the over accumulation of PCL segments influence the twist of PLLA lamellae, which result in the nonbanded structure. Moreover, it was interesting to find that the banding-tononbanding morphological transition occurred with increasing the crystallization temperature and that the banding phenomenon is closely correlated to the interaction among the isothermal crystallization temperature, spherulitic growth rate and lamellar thickness of banded spherulites. The band spacing of PCLLA75 spherulites show weak temperature dependence below $115{ }^{\circ} \mathrm{C}$ because of the competition between the lamellae thickening and the increased spherulitic growth rate. On the contrary, when temperature over $115{ }^{\circ} \mathrm{C}$, the lamellar thickening effect on increasing the band spacing is dominant, which results in the band spacing shows strong temperature dependence. With further increasing the temperature above $125{ }^{\circ} \mathrm{C}$, the synergy effect between the lamellae thickening and the decreased spherulitic growth rate make the lamellar twisting difficult to occur. It is precisely because of the interaction of the lamellar thickening and the change of spherulitic growth rate, the banding-to-nonbanding morphological transition dependency on the temperature occurred, which is beneficial to understanding the morphologies of banded spherulites of block copolymers when exploring the banding phenomenon.

\section{Acknowledgements}

This work is supported by the National Natural Science Foundation of China (No. 51373103); the Science and Technology Department of Sichuan Province, China (No. 2015HH0026); the 
Natural Science Foundation of Hubei Province, China (No. 2014CFB456); and the Research and Development of Science and Technology Plan of Xiangyang City.

\section{Notes and references}

1 A. C. Albertsson and I. K. Varma, Biomacromolecules, 2003, 4, 1466-1486.

2 X. Liao, A. V. Nawaby, P. Whitfield, M. Day, M. Champagne and J. Denault, Biomacromolecules, 2006, 7, 2937-2941.

3 Q. Lan, J. Yu, J. He, F. H. J. Maurer and J. Zhang, Macromolecules, 2010, 43, 8602-8609.

4 S. Li, G. He, X. Liao, C. B. Park, Q. Yang and G. Li, RSC Adv., 2017, 7, 6266-6277.

5 J. K. Kim, D. J. Park, M. S. Lee and K. J. Ihn, Polymer, 2001, 42, 7429-7441.

6 Y. H. Na, Y. He, X. Shuai, Y. Kikkawa, Y. Doi and Y. Inoue, Biomacromolecules, 2002, 3, 1179-1186.

7 X. Wang, H. Zhao, L. S. Turng and Q. Li, Ind. Eng. Chem. Res., 2013, 52, 4939-4949.

8 D. Pappalardo, L. Annunziata and C. Pellecchia, Macromolecules, 2009, 42, 6056-6062.

9 E. J. Choi, J. K. Park and H. N. Chang, J. Polym. Sci., Part B: Polym. Phys., 1994, 32, 2481-2489.

10 M. T. Casas, J. Puiggalí, J. M. Raquez, P. Dubois, M. E. Córdova and A. J. Müller, Polymer, 2011, 52, 5166-5177.

11 D. Shin, K. Shin, K. A. Aamer, G. N. Tew, T. P. Russell, J. H. Lee and J. Y. Jho, Macromolecules, 2005, 38, 104-109.

12 S. Huang, S. Jiang, X. Chen and L. An, Langmuir, 2009, 25, 13125-13132.

13 I. W. Hamley, P. Parras, V. Castelletto, R. V. Castillo, A. J. Müller, E. Pollet, P. Dubois and C. M. Martin, Chem. Phys., 2006, 207, 941-953.

14 E. Laredo, N. Prutsky, A. Bello, M. Grimau, R. V. Castillo, A. J. Müller and P. Dubois, Eur. Phys. J. E, 2007, 23, 295-303.

15 S. Huang, S. Jiang, L. An and X. Chen, J. Polym. Sci., Part B: Polym. Phys., 2008, 46, 1400-1411.

16 R. V. Castillo, A. J. Müller, J. M. Raquez and P. Dubois, Macromolecules, 2010, 43, 4149-4160.

17 J. Wang and C. Dong, Macromol. Chem. Phys., 2006, 207, 554562.

18 G. Sun, L. T. Weng, J. M. Schultz and C. M. Chan, Polymer, 2014, 55, 1829-1836.

19 K. S. Kim, I. J. Chin, J. S. Yoon, H. J. Choi, D. C. Lee and K. H. Lee, J. Appl. Polym. Sci., 2001, 82, 3618-3626.

20 F. Harmansyah, E. M. Woo, L. T. Lee and H. R. Chien, RSC Adv., 2014, 4, 49006-49015.

21 G. Ding and J. Liu, Colloid Polym. Sci., 2013, 291, 1547-1554.

22 Y. Zhang, Z. Wang, F. Jiang, J. Bai and Z. Wang, Soft Matter, 2013, 9, 5771-5778.
23 R. M. Ho, P. Y. Hsieh, W. H. Tseng, C. C. Lin, B. H. Huang and B. Lotz, Macromolecules, 2003, 36, 9085-9092.

24 S. Huang, H. Li, H. Wen, D. Yu, S. Jiang, G. Li, X. Chen and L. An, CrystEngComm, 2014, 16, 94-101.

$25 \mathrm{~J} . \mathrm{Xu}, \mathrm{B} . \mathrm{Guo}, \mathrm{J}$. Zhou, L. Li, J. Wu and M. Kowalczuk, Polymer, 2005, 46, 9176-9185.

26 J. Sun, Z. Hong, L. Yang, Z. Tang, X. Chen and X. Jing, Polymer, 2004, 45, 5969-5977.

27 C. Chao, C. Chen, Y. W. Chiang and R. M. Ho, Macromolecules, 2008, 41, 3949-3956.

28 S. Luo, X. Peng, Y. Chen, T. Su, J. Cao, S. Li and B. He, ePolym., 2015, 15, 15-23.

29 Y. He, Z. Fan, Y. Hu, T. Wu, J. Wei and S. Li, Eur. Polym. J., 2007, 43, 4431-4439.

30 R. V. Castillo and A. J. Müller, Prog. Polym. Sci., 2009, 34, 516560.

31 J. M. Yang, H. L. Chen, J. W. You and J. C. Hwang, Polym. J., 1997, 29, 657-662.

32 N. L. Rodriguez, A. L. Arraiza, E. Meaurio and J. R. Sarasua, Polym. Eng. Sci., 2006, 46, 1299-1308.

33 Q. Zhang, V. N. Mochalin, I. Neitzel, K. Hazeli, J. Niu, A. Kontsos, J. Zhou, P. I. Lelkes and Y. Gogotsi, Biomaterials, 2012, 33, 5067-5075.

34 Y. Shikinami and M. Okuno, Biomaterials, 1999, 20, 859-877. 35 V. Crescenzi, G. Manzini, G. Calzolari and C. Borri, Eur. Polym. J., 1972, 8, 449-463.

36 H. D. Keith and J. F. J. Padden, Polymer, 1984, 25, 28-42.

37 J. Ji, X. Liao, J. Bai, X. Luo, Q. Yang and G. Li, Colloid Polym. Sci., 2015, 293, 2311-2319.

38 J. Li, Z. Hu, Z. Wang, Q. Gu, Y. Wang and Y. Huang, Ind. Eng. Chem. Res., 2013, 52, 1892-1900.

39 Z. Wang, G. C. Alfonso, Z. Hu, J. Zhang and T. He, Macromolecules, 2008, 41, 7584-7595.

40 B. Lotz and S. Z. D. Cheng, Polymer, 2005, 46, 577-610.

41 D. Patel and D. C. Bassett, Polymer, 2002, 43, 3795-3802.

42 H. Ye, J. Wang, S. Tang, J. Xu, X. Feng, B. Guo, X. Xie, J. Zhou, L. Li, Q. Wu and G. Chen, Macromolecules, 2010, 43, 57625770.

43 C. I. Huang, S. H. Tsai and C. M. Chen, J. Polym. Sci., Part B: Polym. Phys., 2006, 44, 2438-2448.

44 S. Sasaki, Y. Sakaki, A. Takahara and T. Kajiyama, Polymer, 2002, 43, 3441-3446.

45 Y. Zhang, H. Fang, Z. Wang, M. Tang and Z. Wang, CrystEngComm, 2014, 16, 1026-1037.

46 J. Li, Y. Li, J. Zhou, J. Yang, Z. Jiang, P. Chen, Y. Wang, Q. Gu and Z. Wang, Macromolecules, 2011, 44, 2918-2925.

47 Q. Zhang, J. Fan and J. Feng, RSC Adv., 2015, 5, 43155-43163. 